\title{
Effects of Ions on the Liquid Crystalline Mesophase of Transition-Metal Salt:Surfactant $\left(\mathrm{C}_{n} \mathbf{E} \mathbf{O}_{m}\right)$
}

\author{
Ömer Dag,* Selim Alayoğlu, and İshak Uysal \\ Chemistry Department, Bilkent University, 06800 Ankara, Turkey
}

Received: January 20, 2004; In Final Form: April 9, 2004

\begin{abstract}
The transition-metal aqua complex salts $\left[\mathrm{M}\left(\mathrm{H}_{2} \mathrm{O}\right)_{x}\right] \mathrm{Y}_{2}$ (where $\mathrm{M}$ is some of the first- and second-row transitionmetal ions and $\mathrm{Y}$ is $\mathrm{Cl}^{-}, \mathrm{NO}_{3}{ }^{-}$, and $\mathrm{ClO}_{4}{ }^{-}$counteranions) form liquid crystalline (LC) mesophases with oligo(ethylene oxide) nonionic surfactants $\left(\mathrm{C}_{n} \mathrm{H}_{2 n+1}\left(\mathrm{CH}_{2} \mathrm{CH}_{2} \mathrm{O}\right)_{m} \mathrm{OH}\right.$, denoted as $\left.\mathrm{C}_{n} \mathrm{EO}_{m}\right)$. The structure of the $\left[\mathrm{M}\left(\mathrm{H}_{2} \mathrm{O}\right)_{x}\right] \mathrm{Y}_{2}: \mathrm{C}_{n} \mathrm{EO}_{m}$ mesophase is usually $2 \mathrm{D}$ hexagonal in nitrate systems, cubic in perchlorate systems, and absent in the chloride systems. The solubility of the metal aqua complex salt follows the Hofmeister series in a $\left[\mathrm{M}\left(\mathrm{H}_{2} \mathrm{O}\right)_{x}\right] \mathrm{Y}_{2}: \mathrm{C}_{n} \mathrm{EO}_{m}$ mesophase. However, the nitrate ion interacts with the metal center as a bidentate and/or unidentate ligand, therefore reducing the ion density (and/or ionic strength) of the LC medium and further enhancing the solubility of nitrate salt in the LC systems. The cobalt chloride salt is the only soluble chloride salt that undergoes ligand-exchange reactions in the $\left[\mathrm{Co}\left(\mathrm{H}_{2} \mathrm{O}\right)_{6}\right] \mathrm{Cl}_{2}: \mathrm{C}_{n} \mathrm{EO}_{m}$ system. In an $\mathrm{LC}$ mesophase, anions have a greater influence on the hydrophilicity of nonionic surfactants than do cations. The structure and stability of the LC mesophase can be controlled by controlling either the hydrophilicity of the nonionic surfactant (by choosing the right anion type) or the ion density of the medium (by either influencing the equilibrium between the free and coordinated anions or balancing between the coordinating and noncoordinating anions in the medium).
\end{abstract}

\section{Introduction}

Recently, a new liquid crystalline (LC) system based on transition-metal salts and oligo(ethylene oxide) nonionic surfactants $\left(\mathrm{C}_{n} \mathrm{H}_{2 n+1}\left(\mathrm{CH}_{2} \mathrm{CH}_{2} \mathrm{O}\right)_{m} \mathrm{OH}\right.$, denoted as $\left.\mathrm{C}_{n} \mathrm{EO}_{m}\right)$ has been introduced. ${ }^{1}$ In the new system, various transition-metal aqua complex salts could be dissolved in $\mathrm{C}_{n} \mathrm{EO}_{m}$, to obtain the LC mesophase. Factors that induce a self-assembly into hexagonal and/or cubic mesophases include the type and concentration of the metal salts $\left[\mathrm{M}\left(\mathrm{H}_{2} \mathrm{O}\right)_{6}\right] \mathrm{Y}_{2}\left(\mathrm{M}=\mathrm{Co}^{2+}, \mathrm{Ni}^{2+}, \mathrm{Zn}^{2+}, \mathrm{Cr}^{3+}\right.$, etc. $)$ and $\left[\mathrm{M}^{\prime}\left(\mathrm{H}_{2} \mathrm{O}\right)_{4}\right]^{2+}\left(\mathrm{M}^{\prime}=\mathrm{Cd}^{2+}\right.$ and $\mathrm{Mn}^{2+} ; \mathrm{X}=\mathrm{Cl}^{-}, \mathrm{NO}_{3}{ }^{-}$, and $\mathrm{ClO}_{4}^{-}$) and the collective interactions of the metal aqua complex ion-surfactant and metal ion-counteranion. ${ }^{1-3}$ Coordination interaction of a nitrate counteranion with a metal ion reduces the ion density (or ionic strength) of the LC medium, enhances solubility, and/or prevents the crystallization of nitrate salts in the LC medium.

The influence of various electrolytes on micelle solutions and on the LC mesophase of $\mathrm{C}_{n} \mathrm{EO}_{m}$ nonionic surfactants has been extensively discussed in the literature. ${ }^{4-9}$ Examples include the influence on the cloud point of a micelle solution, ${ }^{4}$ on the LC mesophase of nonionic surfactants, ${ }^{5-7}$ and on the formation of mesoporous silica materials. ${ }^{8-10}$ According to Hofmeister's series ${ }^{11}\left(\mathrm{SO}_{4}{ }^{2-}>\mathrm{HPO}_{4}{ }^{2-}>\mathrm{CrO}_{4}{ }^{-}>\mathrm{CO}_{3}{ }^{2-}>\mathrm{Cl}^{-}>\mathrm{Br}^{-}>\right.$ $\mathrm{NO}_{3}{ }^{-}>\mathrm{I}^{-}>\mathrm{ClO}_{4}{ }^{-}>\mathrm{SCN}^{-}$), anions on the left-hand side of the series are lyotropic and make surfactant molecules more hydrophobic, and those on the right-hand side are hydrotropic and make the surfactant molecules more hydrophilic. This means the metal salts of anions on the right-hand side should be more soluble. ${ }^{4-9}$ Also note that the metal salts of lyotropic anions (such as $\mathrm{Cl}^{-}, \mathrm{SO}_{4}{ }^{2-}$, etc.) are not soluble in $\mathrm{C}_{n} \mathrm{EO}_{m}$ nonionic surfactants. ${ }^{1}$ One would expect that the perchlorate ion would make the surfactant molecules more hydrophilic than a nitrate

* To whom correspondence should be addressed. Fax: 903122664579. Phone: 90312290 3918. E-mail: dag@fen.bilkent.edu.tr. ion in a water:surfactant system. ${ }^{12}$ However, transition-metal perchlorate salts are harder to dissolve compared to nitrate salts in a salt:surfactant LC system. ${ }^{3}$

Recent developments in the literature regarding the synthesis of mesoporous, mesostructured, and nanostructured materials synthesized using $\mathrm{C}_{n} \mathrm{EO}_{m}$ nonionic surfactants as templating agents $^{13-32}$ show the demand and significance of salt:nonionic surfactant LC systems. Since the metal ion concentration in the new LC system could be increased up to a $60-65(\% \mathrm{w} / \mathrm{w})$ salt-to-surfactant ratio (ca. 6-6.5 molecules of metal ion per $\left.\mathrm{C}_{12} \mathrm{EO}_{10}\right),{ }_{1}^{1}$ mesostructured metal sulfides, ${ }^{3}$ metal selenides, metal oxides, and/or metals produced using the new mesophase may have advantages over other methods in the literature, ${ }^{13-18}$ such as higher yield, larger mesostructured particles, even mesoporous thin films, etc. The mesostructured and/or nanostructured metal sulfides have been synthesized by using water:salt:surfactant LC mesophases, in high water $(50 \% \mathrm{w} / \mathrm{w}$ water:surfactant) and low salt (typically $0.1 \mathrm{M}$ salt $\mathrm{Cd}\left(\mathrm{NO}_{3}\right)_{2}$ solutions) concentrations and $\mathrm{H}_{2} \mathrm{~S}$ gas $^{3,15-17}$ or thioacetoamide ${ }^{18}$ as a sulfur source. However, the $\mathrm{LC}$ phase of a $\mathrm{H}_{2} \mathrm{O}: \mathrm{Cd}\left(\mathrm{NO}_{3}\right)_{2}: \mathrm{C}_{n} \mathrm{EO}_{m}$ mixture is only stable at low salt:surfactant ratios ${ }^{13-21}$ and liquid at higher salt concentrations (no mesophase).

In this paper, the structural behavior of various transitionmetal salts in $\left[\mathrm{M}\left(\mathrm{H}_{2} \mathrm{O}\right)_{x}\right] \mathrm{Y}_{2}: \mathrm{H}_{2} \mathrm{O}: \mathrm{C}_{n} \mathrm{EO}_{m} \mathrm{LC}$ mesophases, going from water-rich salt:water:surfactant (ternary systems) to almostwater-free salt:surfactant (binary systems), a correlation with the coordination of a counteranion to a transition-metal ion, and the effect of chloride, perchlorate, nitrate, and mixed ions on the LC mesophase will be discussed by means of microscopy, spectroscopy, and diffraction methods.

Throughout this work, $\mathrm{C}_{12} \mathrm{EO}_{10}$ as a surfactant source and $\left[\mathrm{Co}\left(\mathrm{H}_{2} \mathrm{O}\right)_{6}\right] \mathrm{Cl}_{2}, \quad\left[\mathrm{Ni}\left(\mathrm{H}_{2} \mathrm{O}\right)_{6}\right]\left(\mathrm{NO}_{3}\right)_{2}, \quad\left[\mathrm{Cd}\left(\mathrm{H}_{2} \mathrm{O}\right)_{4}\right]\left(\mathrm{NO}_{3}\right)_{2}$, [Mn$\left.\left(\mathrm{H}_{2} \mathrm{O}\right)_{4}\right]\left(\mathrm{NO}_{3}\right)_{2},\left[\mathrm{Cr}\left(\mathrm{H}_{2} \mathrm{O}\right)_{6}\right]\left(\mathrm{ClO}_{4}\right),\left[\mathrm{Zn}\left(\mathrm{H}_{2} \mathrm{O}\right)_{6}\right]\left(\mathrm{ClO}_{4}\right)_{2}$, and [Co$\left.\left(\mathrm{H}_{2} \mathrm{O}\right)_{6}\right]\left(\mathrm{ClO}_{4}\right)_{2}$ as salt sources have been extensively studied. 


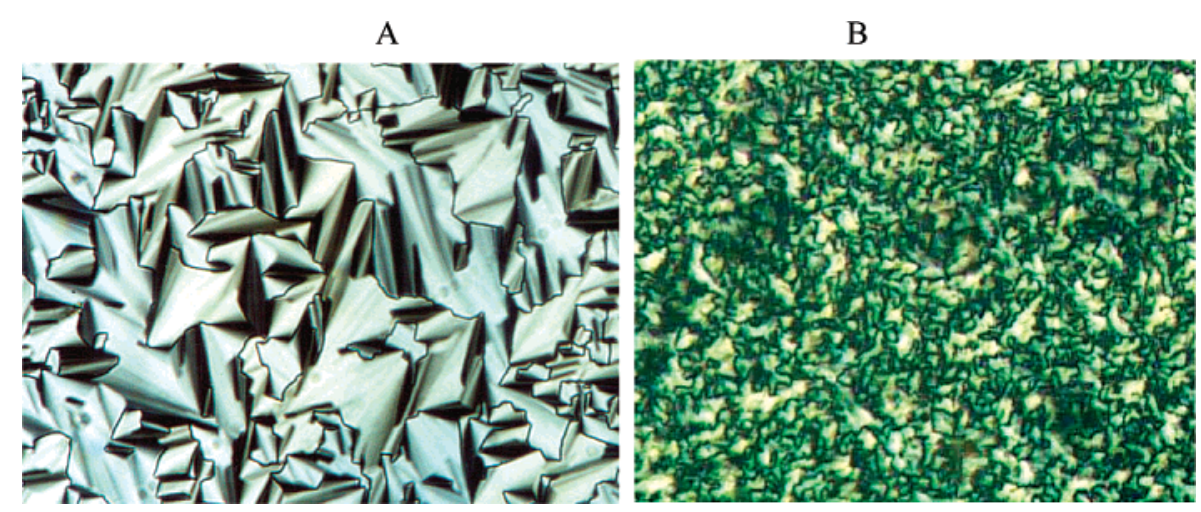

Figure 1. Polarized optical microscopy images of (A) the focal conic fan texture of a $2 \mathrm{D}$ hexagonal $\left[\mathrm{Ni}_{(}\left(\mathrm{H}_{2} \mathrm{O}\right)_{6}\right]\left(\mathrm{NO}_{3}\right)_{2}: \mathrm{C}_{12} \mathrm{EO}_{10}$ and $(\mathrm{B})$ a $3 \mathrm{D}$ hexagonal $\left[\mathrm{Mn}\left(\mathrm{H}_{2} \mathrm{O}\right)_{4}\right]\left(\mathrm{NO}_{3}\right)_{2}: \mathrm{C}_{12} \mathrm{EO}_{10}$.

\section{Experimental Section}

Materials and Sample Preparation. The surfactants $\mathrm{C}_{12}{ }^{-}$ $\mathrm{EO}_{4}, \mathrm{C}_{12} \mathrm{EO}_{10}, \mathrm{C}_{12} \mathrm{EO}_{23}$, and $\mathrm{C}_{16} \mathrm{EO}_{10}$ and all the transition-metal salts were obtained from Aldrich or Fluka and used without further purification. The binary salt:surfactant samples were prepared using the previously published method. ${ }^{1}$ The ternary samples are prepared by first dissolving the appropriate amount of salts in various amounts of water and then to the resulting clear solution adding $1.00 \mathrm{~g}$ of surfactant. The resulting mixture is homogenized by heating to its melting point in sealed vials. Note that some samples are already liquid at this stage. Therefore, homogenizing the ternary samples is quite easy.

Instrumentation. Polarized optical microscopy (POM) images were recorded at room temperature (RT) on samples which were heated to above their isotropization temperatures (ITs), and then cooled to RT. The POM images were monitored in transmittance mode on a Meije Techno ML9400 series polarizing microscope with reflected and transmitted light illumination, using convergent white light between the parallel and crossed polarizers. The images were recorded using a stereomicroscope Stemi 2000 from Carl Ziess Jena GmbH with a halogen lamp 6V/10W equipped for bright field and phase contrast. The thermal properties of the mixtures were studied using a Leica microscope heating stage 350 attached to the Meije Techno ML9400 microscope. The hot stage, which was calibrated against the melting point of naphthalene, was operated with a $3{ }^{\circ} \mathrm{C} / \mathrm{min}$ heating rate. X-ray diffraction (XRD) patterns of LC samples that were packed into 0.5 or $0.2 \mathrm{~mm}$ glass sample holders were recorded on a Rigaku Miniflex diffractometer using a high-power $\mathrm{Cu} \mathrm{K} \alpha$ source operating at $30 \mathrm{kV} / 15$ $\mathrm{mA}$. The XRD patterns were recorded for each sample in the $2 \theta=1.0-5.0^{\circ}$ range. Fourier transform infrared (FTIR) spectra were recorded using a Bomem Hartman MB-102 model FTIR spectrometer with a standard DTGS detector, a resolution of 4 $\mathrm{cm}^{-1}$, and 16 or 32 scans for thin film samples that are prepared on a silicon wafer. FTIR spectra of water-containing samples were recorded by sandwiching the samples between two silicon wafers. UV-vis/near-IR spectra were recorded using a Varian Cary 5 double-beam spectrophotometer with a $150 \mathrm{~nm} / \mathrm{min}$ scan speed and a resolution of $2 \mathrm{~nm}$ over wavelength ranges from 1400 to $200 \mathrm{~nm}$ and from 800 to $400 \mathrm{~nm}$. The UV-vis absorption measurements were recorded on glass slides and/or quartz windows. Micro-Raman spectra were recorded on a LabRam confocal Raman microscope with a $300 \mathrm{~mm}$ focal length. The spectrometer is equipped with a HeNe laser operated at $20 \mathrm{~mW}$, polarized 500:1 with a wavelength of $632.817 \mathrm{~nm}$, and a $1024 \times 256$ element CCD camera. The signal collected was transmitted through a fiber optic cable into a grating with a 1800 or $600 \mathrm{~g} / \mathrm{mm}$ spectrometer. The Raman spectra were collected by manually placing the probe tip near the desired point of the sample on a glass slide.

\section{Results and Discussion}

The LC mesophases of $\left[\mathrm{M}\left(\mathrm{H}_{2} \mathrm{O}\right)_{x}\right] \mathrm{Y}_{2}: \mathrm{C}_{n} \mathrm{EO}_{m}$ have been prepared by dissolving transition-metal chloride, perchlorate, and nitrate salts of various aqua complexes of transition metals in $\mathrm{C}_{n} \mathrm{EO}_{m}$ (where $n=12$ and $m=4,10$, and 23) and $\mathrm{C}_{16} \mathrm{EO}_{10}$ nonionic surfactants (binary systems). To expand, the samples were also prepared in the presence of water as a third component of the phase (ternary systems). Both the binary and ternary mixtures were homogenized by heating and cooling cycles in closed vials prior to mixing. The ternary samples, which are also used to prepare binary LC samples by evaporating their excess water, are easier to prepare and homogenize. The textures of the POM images, XRD patterns, and micro-Raman and FTIR spectra of a binary system prepared by evaporating the water content of its ternary mixture are identical to those of a binary mixture that is prepared without water. All samples used throughout this work were characterized using a temperaturecontrolled heating stage in POM, micro-Raman spectroscopy, FTIR spectroscopy, UV-Vis absorption spectroscopy, and XRD techniques. FTIR spectroscopy for nitrate and perchlorate and $\mathrm{UV}$ - vis absorption spectroscopy for chloride systems have been used extensively to elucidate the nature of the interaction of metal ion-counteranion and metal ion-surfactant molecules and the influence of various ions on the LC mesophase.

$\left[\mathbf{M}\left(\mathrm{H}_{2} \mathrm{O}\right)_{6}\right]\left(\mathrm{NO}_{3}\right)_{2}: \mathbf{C}_{12} \mathbf{E O}_{10}$ Systems. In general, the POM images of $\left[\mathrm{M}\left(\mathrm{H}_{2} \mathrm{O}\right)_{x}\right]\left(\mathrm{NO}_{3}\right)_{2}: \mathrm{C}_{12} \mathrm{EO}_{10}$ samples display a focal conic fan texture, characteristic of a 2D hexagonal mesophase, Figure 1A. The manganese nitrate binary system, mixed-metal nitrate/metal perchlorate systems (will be discussed later) with certain nitrate-to-perchlorate ratios, and other metal nitrates in ternary systems within certain water concentrations display images such as those shown in Figure 1B. The XRD patterns of $\left[\mathrm{Ni}\left(\mathrm{H}_{2} \mathrm{O}\right)_{6}\right]\left(\mathrm{NO}_{3}\right)_{2}: \mathrm{C}_{12} \mathrm{EO}_{10}$ samples with focal conic fan texture display diffraction lines at around $2 \theta=1.84^{\circ}, 3.06^{\circ}$, $3.59^{\circ}, 4.64^{\circ}$, and $5.25^{\circ}$ corresponding to the (10), (11), (20), (21), and (30) planes of the $P 6 \mathrm{~mm}$ space group of a $2 \mathrm{D}$ hexagonal mesophase, Figure 2A. However, the manganese nitrate and some of the mixed-salt systems display diffraction lines characteristic of a 3D hexagonal mesophase. Figure $2 \mathrm{~B}$ displays a diffraction pattern of $2\left[\mathrm{Mn}\left(\mathrm{H}_{2} \mathrm{O}\right)_{4}\right]\left(\mathrm{NO}_{3}\right)_{2}: \mathrm{C}_{12} \mathrm{EO}_{10}$. The diffraction pattern consists of seven lines at $2 \theta=1.69^{\circ}$, $1.79^{\circ}, 1.90^{\circ}, 2.21^{\circ}, 2.39^{\circ}, 2.65^{\circ}$, and $3.54^{\circ}$ corresponding to the (100), (002), (101), (102), (003), (110), and (004) planes, respectively, with $a=60.4 \AA, c=98.1 \AA$, and $c / a=1.632$ 
A

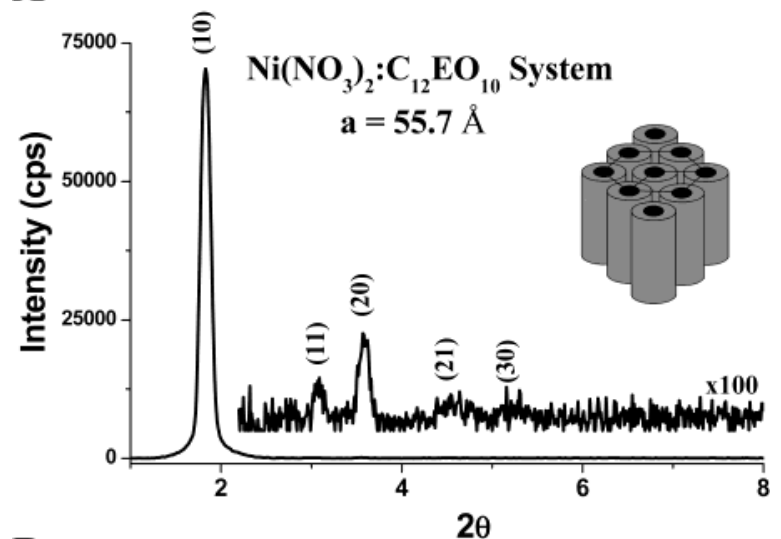

B

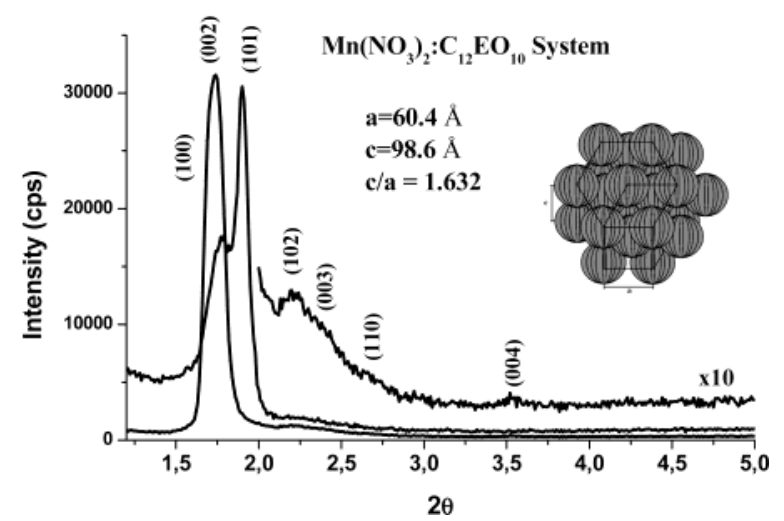

Figure 2. XRD pattern of (A) a $2 \mathrm{D}$ hexagonal mesophase recorded from $\left[\mathrm{Ni}\left(\mathrm{H}_{2} \mathrm{O}\right)_{6}\right]\left(\mathrm{NO}_{3}\right)_{2}: \mathrm{C}_{12} \mathrm{EO}_{10}$ (a salt:surfactant mole ratio of 2.0; the inset is a schematic diagram for a $2 \mathrm{D}$ hexagonal structure) and (B) a $3 \mathrm{D}$ hexagonal mesophase of $\left[\mathrm{Mn}\left(\mathrm{H}_{2} \mathrm{O}\right)_{4}\right]\left(\mathrm{NO}_{3}\right)_{2}: \mathrm{C}_{12} \mathrm{EO}_{10}$ (a salt: surfactant mole ratio of 2.0; the inset is a schematic diagram for a $3 \mathrm{D}$ hexagonal structure).

corresponding to the $P 6_{3} \mathrm{~mm}$ space group of a $3 \mathrm{D}$ hexagonal mesophase. Throughout this work, the structure of the LC mesophase was identified collectively using POM and XRD techniques.

The mixtures of $\left[\mathrm{M}\left(\mathrm{H}_{2} \mathrm{O}\right)_{x}\right]\left(\mathrm{NO}_{3}\right)_{2}: \mathrm{H}_{2} \mathrm{O}: \mathrm{C}_{n} \mathrm{EO}_{m}$ are usually liquid at high water concentrations, display birefringent texture in POM (characteristic of a 3D hexagonal phase) at a moderate water concentration, and undergo phase changes and become $2 \mathrm{D}$ hexagonal upon complete water evaporation. The samples with moderate water concentrations have two diffraction lines at low angles that correspond to the (100) and (101) planes of a $3 \mathrm{D}$ hexagonal phase.

To elucidate the phase changes, a mixture of $\left[\mathrm{Zn}\left(\mathrm{H}_{2} \mathrm{O}\right)_{6}\right]-$ $\left(\mathrm{NO}_{3}\right)_{2}: \mathrm{H}_{2} \mathrm{O}: \mathrm{C}_{12} \mathrm{EO}_{10}$ with a composition of 2.5:35:1.0 (mole ratio), respectively, was monitored during the water evaporation process by FTIR. Figure 3 shows the changes in the mid-IR spectra with time. The first spectrum recorded between two silicon wafers displays a broad peak at around $1364 \mathrm{~cm}^{-1}$ indicating the presence of a free nitrate ion (not shown). With the evaporation of water, the peak due to the free nitrate ion decreases in intensity, and two new peaks at 1302 and 1460 $\mathrm{cm}^{-1}$ due to coordinated nitrate ion appear and gain intensity with further water evaporation. ${ }^{2}$ Note that the coordination of the nitrate ion to the metal ion reduces the symmetry of the free nitrate ion from $D_{3 h}$ to $C_{2 v}$, such that the doubly degenerate asymmetric stretching mode $\left(\mathrm{E}^{\prime}\right)$ splits into two $\left(\mathrm{B}_{2}\right.$ and $\left.\mathrm{A}_{1}\right)$ and the inactive symmetric stretching mode becomes active and is observed at $1030 \mathrm{~cm}^{-1}$. In all nitrate samples, signals of a
A)
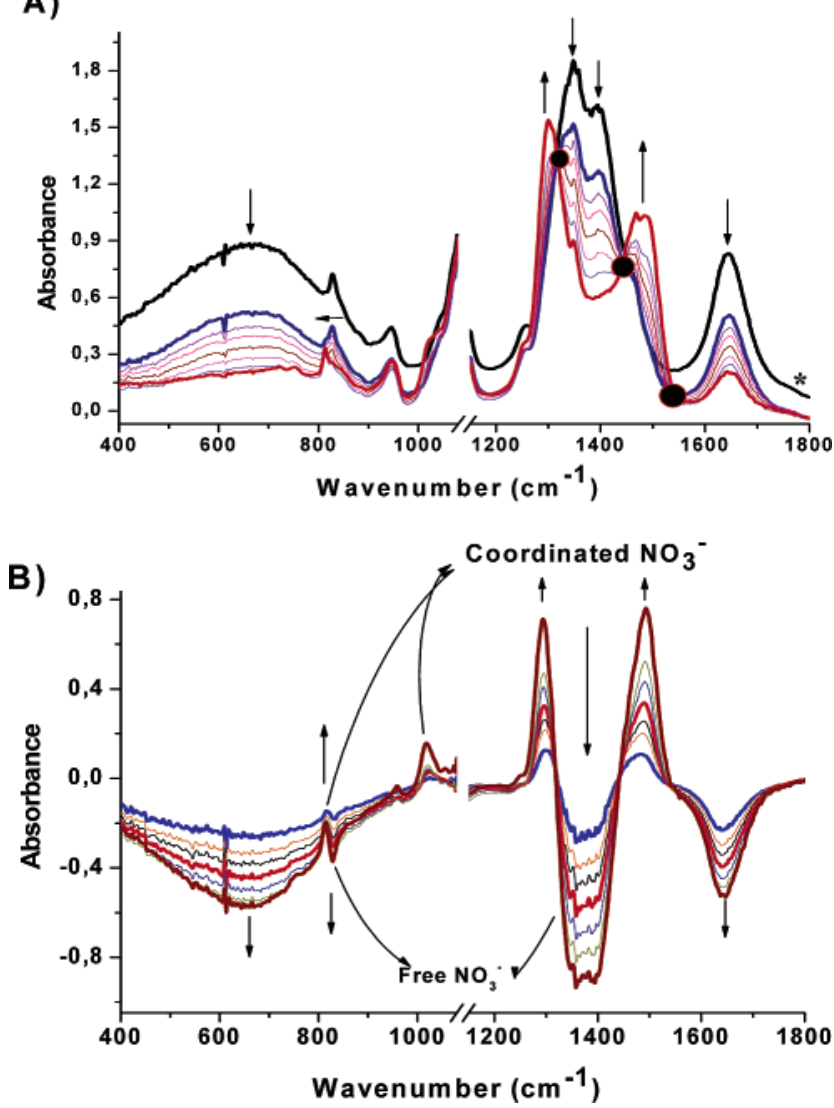

Figure 3. (A) FTIR spectral changes during the water evaporation steps of a $\left[\mathrm{Zn}\left(\mathrm{H}_{2} \mathrm{O}\right)_{6}\right]\left(\mathrm{NO}_{3}\right)_{2}: \mathrm{H}_{2} \mathrm{O}: \mathrm{C}_{12} \mathrm{EO}_{10}$ system. The top spectrum (*) was recorded right after the film sample on silicon was prepared from a $1.00 \mathrm{~g}$ water-containing sample (the excess water contents from top to bottom are $0.52,0.31,0.24,0.17,0.15,0.12$, and $0.04 \mathrm{~g} / \mathrm{g}$ of surfactant; the salt-to-surfactant mole ratio is 2.5). (B) Difference spectra between the first and other measurements.

coordinated nitrate ion appear and intensify at around the nitrate asymmetric stretching region during the water evaporation process, Figure 3A. Figure 3B shows the difference spectra to better visualize the changes between the first spectrum recorded from the sample $25 \mathrm{H}_{2} \mathrm{O}: 2.5\left[\mathrm{Zn}\left(\mathrm{H}_{2} \mathrm{O}\right)_{6}\right]\left(\mathrm{NO}_{3}\right)_{2}: 1.0 \mathrm{C}_{12} \mathrm{EO}_{10}$ (marked with an asterisk in Figure $3 \mathrm{~A}$ ) on a single $\mathrm{Si}(100)$ wafer and consecutive spectra recorded from the same sample during the water evaporation process. In the presence of excess water, the free nitrate ion dominates in the liquid and/or LC mesophase, Figure 3A, marked with an asterisk. However, upon evaporation of excess water in the mixtures (or the samples prepared with reduced water content), the coordinated water molecules undergo a ligand-exchange reaction with the nitrate ions, producing $\left[\mathrm{M}\left(\mathrm{H}_{2} \mathrm{O}\right)_{4-x}\left(\mathrm{NO}_{3}\right)\right]^{+}$complex species. ${ }^{2}$ The spectral changes and the observed isosbestic points at 1545,1445 , and $1317 \mathrm{~cm}^{-1}$ (see Figure 3 ) clearly show an equilibrium (eq 1) between the free and coordinated nitrate ion species.

$$
\begin{aligned}
{\left[\mathrm{M}\left(\mathrm{H}_{2} \mathrm{O}\right)_{n}\right]^{+}+2 } & \mathrm{NO}_{3}^{-} \rightleftharpoons \\
& {\left[\mathrm{M}\left(\mathrm{H}_{2} \mathrm{O}\right)_{n-x}\left(\mathrm{NO}_{3}\right)\right]^{+}+\mathrm{NO}_{3}{ }^{-}+2 \mathrm{H}_{2} \mathrm{O} }
\end{aligned}
$$

Note also that coordination of nitrate ion to a metal center makes the complex ion +1 charged $\left(\left[\mathrm{M}\left(\mathrm{H}_{2} \mathrm{O}\right)_{n-x}\left(\mathrm{O}_{2} \mathrm{NO}\right)\right]^{+}\right.$, where $x$ is 1 or 2 for unidentate or bidentate coordination, respectively) rather than +2 charged $\left(\left[\mathrm{M}\left(\mathrm{H}_{2} \mathrm{O}\right)_{n}\right]^{2+}\right.$ in the free ion case) and drops the free nitrate ion concentration in the medium. 


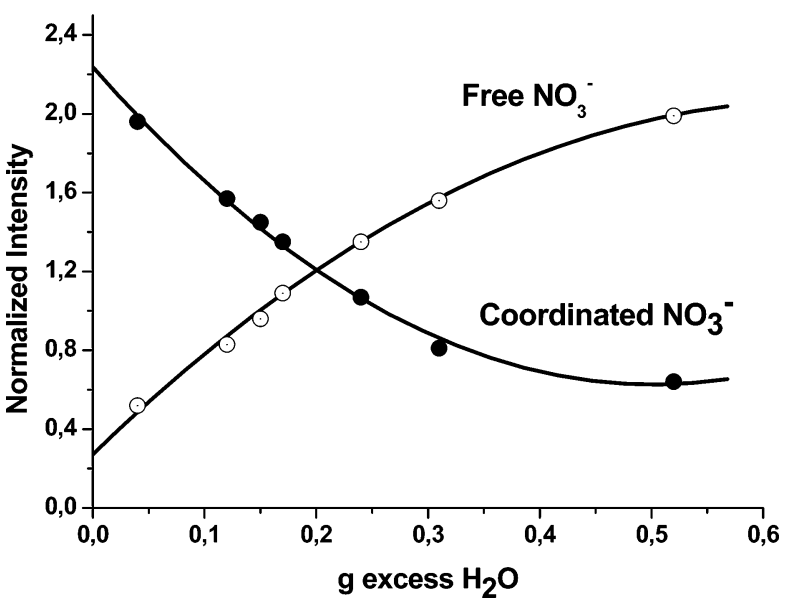

Figure 4. Absorbance of the free nitrate ion versus mass $(\mathrm{g})$ of water $(\mathrm{O})$ and coordinated nitrate ion versus mass $(\mathrm{g})$ of water $(\mathbf{)})$ with time of the system in Figure 3A (the high to low water concentration axis is also the time axis).

The water content of each step was determined spectroscopically. For this, the IR spectra of a series of samples prepared with known water content were measured between two Si(100) wafers to protect the evaporation of water during the measurements (note that sandwiched samples show no time-dependent changes and no water evaporation during the measurements). The intensity of the water bending mode of the samples with known water content was plotted against water concentration. The thickness of each sample was normalized using the absorption band at $946 \mathrm{~cm}^{-1}$ of the surfactant molecule. Note also that the peak intensity at $946 \mathrm{~cm}^{-1}$ does not change with the evaporation of water, Figure 3A. The plot obeys Beer's law. The least-squares fit gives a slope of $1.358( \pm 0.047)$ and intercept of $0.187( \pm 0.020)$ (not shown). The plot was used to determine the free water content of the unknown samples by normalizing the film thickness of the unknown samples against the band at $946 \mathrm{~cm}^{-1}$ with an absorbance of 0.320 . The peak intensities of free and coordinated nitrate ions, convoluted from the spectra in Figure 3A versus water concentration (in grams, obtained using the spectra in Figure 3A) follow a second-order dependence on water concentration, Figure 4. Therefore, for each nitrate coordinated, two water molecules are liberated from the coordination sphere, indicating a bidentate coordination of the nitrate ion to the metal ion center.

The water content of the samples that are used for XRD measurements was also determined by means of spectroscopy. At various steps in the XRD measurements, some samples were taken from the XRD sample holder for FTIR measurements. Figure 5 shows the changes in the XRD patterns of a $\left[\mathrm{Ni}_{(}\left(\mathrm{H}_{2} \mathrm{O}\right)_{6}\right]$ $\left(\mathrm{NO}_{3}\right)_{2}: \mathrm{H}_{2} \mathrm{O}: \mathrm{C}_{12} \mathrm{EO}_{10} \mathrm{LC}$ system (the salt:water:surfactant mole ratio is 2.0:1.0:35, corresponding to 22.6:38.7:38.7 (\% w/w)) with time. The mixture is liquid until the water-to-surfactant ratio drops to 26.1:29.1:44.8 (\% w/w). The top diffraction pattern in Figure 5 displays two lines at 50.7 and $41.6 \AA d$ spacing around a $\left[\mathrm{Ni}\left(\mathrm{H}_{2} \mathrm{O}\right)_{6}\right]\left(\mathrm{NO}_{3}\right)_{2}: \mathrm{H}_{2} \mathrm{O}: \mathrm{C}_{12} \mathrm{EO}_{10}$ composition of 30.3: 17.7:52 (\% w/w), respectively, definitely not characteristic of a $2 \mathrm{D}$ hexagonal mesophase. The $3 \mathrm{D}$ hexagonal phase of [Ni$\left.\left(\mathrm{H}_{2} \mathrm{O}\right)_{6}\right]\left(\mathrm{NO}_{3}\right)_{2}: \mathrm{H}_{2} \mathrm{O}: \mathrm{C}_{12} \mathrm{EO}_{10}$ appears at around 26.1:29.1:44.8 $(\% \mathrm{w} / \mathrm{w})$ until the content changes to around 35.0:4.8:60.2 (\% $\mathrm{w} / \mathrm{w})$. With further water evaporation, the structure of the mesophase becomes 2D hexagonal. Note also that some of the $\left.\left[\mathrm{Cd}\left(\mathrm{H}_{2} \mathrm{O}\right)_{4}\right]\left(\mathrm{NO}_{3}\right)_{2}\right]: \mathrm{H}_{2} \mathrm{O}: \mathrm{C}_{12} \mathrm{EO}_{10}$ samples have three diffraction lines, which could be indexed to (100), (002), and (101) lines of a $3 \mathrm{D}$ hexagonal structure during the water evaporation process

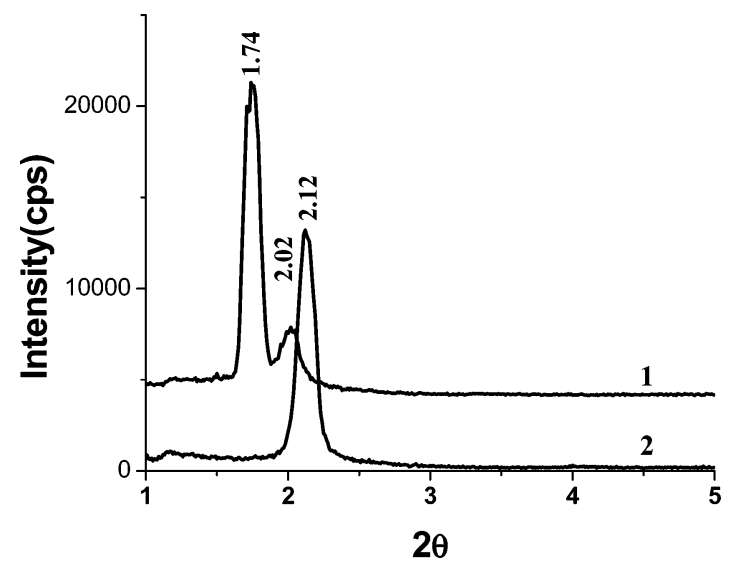

Figure 5. XRD pattern of $\left[\mathrm{Cd}\left(\mathrm{H}_{2} \mathrm{O}\right)_{4}\right]\left(\mathrm{NO}_{3}\right)_{2}: \mathrm{H}_{2} \mathrm{O}: \mathrm{C}_{12} \mathrm{EO}_{10}$ in time with compositions (1) 12:2.0:1.0 (mole ratio) and (2) 0.0:2.0:1.0 (mole ratio).

(not shown). The unit cell parameters $a=65.6 \AA$ and $c=106.2$ $\AA$ with $c / a=1.636$ calculated from the sample $2\left[\mathrm{Cd}\left(\mathrm{H}_{2} \mathrm{O}\right)_{4}\right]-$ $\left.\left(\mathrm{NO}_{3}\right)_{2}\right]: 12 \mathrm{H}_{2} \mathrm{O}: \mathrm{C}_{12} \mathrm{EO}_{10}$ (ca. 31.5:17.4:51.1 (\% w/w)) is also consistent with a 3D hexagonal mesophase. In time and with further water evaporation (note the water content at this stage is below $5.0 \% \mathrm{w} / \mathrm{w}$ ), only one diffraction line that shifts to higher $2 \theta$ is observed. The POM image of this composition has a nice focal conic fan texture characteristic of a $2 \mathrm{D}$ hexagonal mesophase; see Figure 1A. The other salt systems $\left[\mathrm{M}\left(\mathrm{H}_{2} \mathrm{O}\right)_{6}\right]-$ $\left(\mathrm{NO}_{3}\right)_{2}: \mathrm{H}_{2} \mathrm{O}: \mathrm{C}_{12} \mathrm{EO}_{10}\left(\mathrm{M}=\mathrm{Zn}^{2+}, \mathrm{Co}^{2+}\right)$ also have similar behaviors. The general trend is that the XRD pattern of mixtures changes with the evaporation of water; after $10 \mathrm{~min}$ to 1 day depending on the thickness and metal ion, it usually displays one peak, which corresponds to the (100) line of a 2D hexagonal mesophase with a focal conic fan texture characteristic of a 2D hexagonal mesophase. The unit cell parameter $a$ decreases from 65.6 to $54.6 \AA$ during the evaporation of water. This corresponds to a $17 \%$ shrinkage. Since the nitrate ion coordinates to the metal ion and water evaporates from the hydrophilic regions of the phase, shrinking by $17 \%$ is not unexpected.

The 3D hexagonal mesophase is commonly observed in the mesoporous and/or mesostructured materials where the nonionic surfactants are used as a templating agent. ${ }^{13-32}$ However, a 3D hexagonal phase is a rare phase in lyotropic liquid crystalline systems. The LC systems behave more like the mesostructured materials, such that the 3D hexagonal mesophase could be observed from some metal nitrates and metal nitrate/metal perchlorate mixed-salt systems. Most likely the function of metal aqua complexes in the LC mesophases is similar to that of silica or other metal oxide species in the true liquid crystalline templating systems of metal oxides. ${ }^{21-25,30,31}$ Note also that the synthesis of mesostructured silica ${ }^{23}$ or titania ${ }^{24}$ in the LC mesophase of nonionic surfactant produces an intermediate metallotropic LC mesophase just before the phase becomes solid with further polymerization of silica or titania species, respectively. The salt: $\mathrm{C}_{n} \mathrm{EO}_{m} \mathrm{LC}$ systems could be categorized in the same group as silicatropic ${ }^{23}$ or titanotropic ${ }^{24}$ LC mesophases.

Other Salt: $\mathbf{C}_{n} \mathbf{E O}_{m}$ Systems. The perchlorate salts are more difficult to dissolve in a nonionic surfactant. Prior to the perchlorate salts being homogeneously dissolved, the $\left[\mathrm{M}\left(\mathrm{H}_{2} \mathrm{O}\right)_{x}\right]-$ $\left(\mathrm{ClO}_{4}\right)_{2}: \mathrm{C}_{n} \mathrm{EO}_{m}$ mixture forms a cubic LC mesophase. ${ }^{3}$ However, the perchlorate ions in a salt:water:surfactant system do not respond to the water content. There is no change in the FTIR or Raman spectra of the perchlorate samples compared to their water-free $\left[\mathrm{M}\left(\mathrm{H}_{2} \mathrm{O}\right)_{x}\right]\left(\mathrm{ClO}_{4}\right)_{2}: \mathrm{C}_{n} \mathrm{EO}_{m}$ counterparts. The perchlorate systems will be further discussed under the content of mixed-salt systems (see below). 


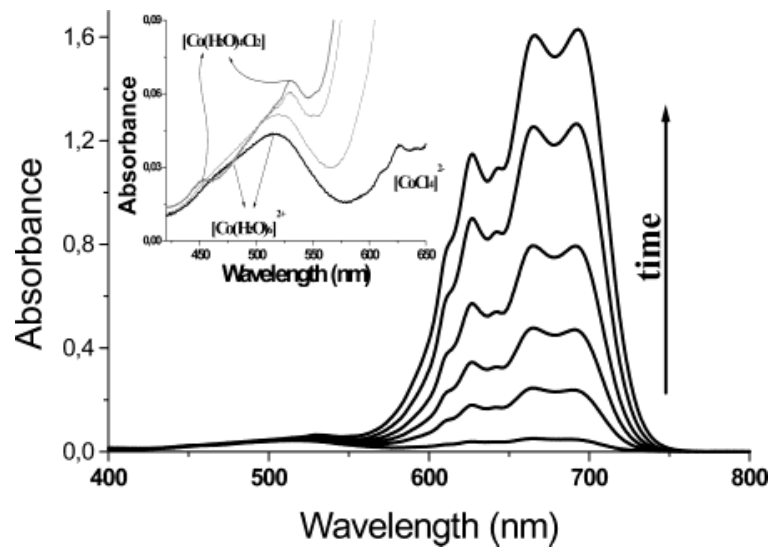

Figure 6. UV-vis absorption spectral changes during the water evaporation process of $\left[\mathrm{Co}\left(\mathrm{H}_{2} \mathrm{O}\right)_{6}\right] \mathrm{Cl}_{2}: \mathrm{H}_{2} \mathrm{O}: \mathrm{C}_{n} \mathrm{EO}_{m}$ (the inset shows the expanded, 400-600 $\mathrm{nm}$ spectral range with complex and complex ion species).

The chloride salts are generally insoluble in nonionic surfactants. The only soluble chloride salt is $\left[\mathrm{Co}\left(\mathrm{H}_{2} \mathrm{O}\right)_{6}\right] \mathrm{Cl}_{2}$ in a $\left[\mathrm{Co}\left(\mathrm{H}_{2} \mathrm{O}\right)_{6}\right] \mathrm{Cl}_{2}: \mathrm{C}_{n} \mathrm{EO}_{m}$ system. ${ }^{1}$ The $\left[\mathrm{Co}\left(\mathrm{H}_{2} \mathrm{O}\right)_{6}\right] \mathrm{Cl}_{2}$ salt forms a sharp-blue-colored LC mesophase in all four nonionic surfactants $\left(\mathrm{C}_{12} \mathrm{EO}_{23}, \mathrm{C}_{12} \mathrm{EO}_{4}, \mathrm{C}_{16} \mathrm{EO}_{10}\right.$, and $\left.\mathrm{C}_{12} \mathrm{EO}_{10}\right)$ tested in this work in various salt:surfactant mole ratios. The blue color originates from the $\mathrm{CoCl}_{4}{ }^{2-}$ ion ${ }^{33}$ in the LC mesophase. Dissolving the $\left[\mathrm{Co}\left(\mathrm{H}_{2} \mathrm{O}\right)_{6}\right] \mathrm{Cl}_{2}$ salt in a nonaqueous solvent or medium ${ }^{1,33}$ enforces coordinated water and free $\mathrm{Cl}^{-}$ions to undergo ligand-exchange reactions to produce the $\left[\mathrm{CoCl}_{4}\right]^{2-}$ ion, which enhances the solubility of the $\left[\mathrm{Co}\left(\mathrm{H}_{2} \mathrm{O}\right)_{6}\right] \mathrm{Cl}_{2}$ salt in a $\left[\mathrm{Co}\left(\mathrm{H}_{2} \mathrm{O}\right)_{6}\right] \mathrm{Cl}_{2}: \mathrm{C}_{n} \mathrm{EO}_{m}$ system. Again the phase obtained using cobalt chloride has a focal conic fan texture between the crossed polarizers.

The solubility of the $\left[\mathrm{Co}\left(\mathrm{H}_{2} \mathrm{O}\right)_{6}\right] \mathrm{Cl}_{2}$ salt has a key importance in the formation of an LC mesophase. For example, if one dissolves the chloride salt of any other transition-metal aqua complex (such as $\left[\mathrm{Ni}\left(\mathrm{H}_{2} \mathrm{O}\right)_{6}\right] \mathrm{Cl}_{2}$ ) in a minimum amount of methanol or water and mixes the resulting solution with $\mathrm{C}_{12}$ $\mathrm{EO}_{10}$, a hexagonal LC mesophase forms. However, the LC phase is not stable in the long term, as it collapses upon solvent evaporation and leaches out the $\left[\mathrm{Ni}\left(\mathrm{H}_{2} \mathrm{O}\right)_{6}\right] \mathrm{Cl}_{2}$ crystals.

The liquid and LC samples with enough water content are purple in color and change to a sharp blue with the evaporation of excess water molecules. The evaporation of excess water was monitored by UV-vis/near-IR spectrophotometry in the visible region; see Figure 6. The low energy and intense absorption bands at around $690 \mathrm{~nm}$, which gradually increase in intensity with the evaporation of water molecules, originate from the $\left[\mathrm{CoCl}_{4}\right]^{2-}$ ion, ${ }^{34}$ Figure 6 . A neutral complex also forms during the water evaporation process (peaks at 454 and $530 \mathrm{~nm}$ are characteristic of the $\left[\mathrm{Co}\left(\mathrm{H}_{2} \mathrm{O}\right)_{4} \mathrm{Cl}_{2}\right]$ neutral complex $\left.{ }^{34}\right)$. It is clear from the trend in the absorption spectra that there is an equilibrium among $\left[\mathrm{Co}\left(\mathrm{H}_{2} \mathrm{O}\right)_{4} \mathrm{Cl}_{2}\right]$ neutral and $\left[\mathrm{Co}\left(\mathrm{H}_{2} \mathrm{O}\right)_{6}\right]^{2+},\left[\mathrm{CoCl}_{4}\right]^{2-}$ ion complexes. Typically, the equilibrium (eq 2) is established upon water evaporation after 10-20 min at RT, depending on the film thickness. The spectrum after equilibrium is achieved does not change in time and is identical to that of an LC binary $\left[\mathrm{Co}\left(\mathrm{H}_{2} \mathrm{O}\right)_{4} \mathrm{Cl}_{2}\right]: \mathrm{C}_{12} \mathrm{EO}_{10}$.

$$
\begin{aligned}
& n\left[\mathrm{Co}\left(\mathrm{H}_{2} \mathrm{O}\right)_{6}\right]^{2+}+(2 n) \mathrm{Cl}^{-} \rightleftharpoons \\
& ((n-m) / 2)\left[\mathrm{Co}\left(\mathrm{H}_{2} \mathrm{O}\right)_{6}\right]^{2+}+(3 n-m) \mathrm{H}_{2} \mathrm{O}+ \\
& ((n-m) / 2)\left[\mathrm{CoCl}_{4}\right]^{2-}+m\left[\mathrm{Co}\left(\mathrm{H}_{2} \mathrm{O}\right)_{4} \mathrm{Cl}_{2}\right]
\end{aligned}
$$

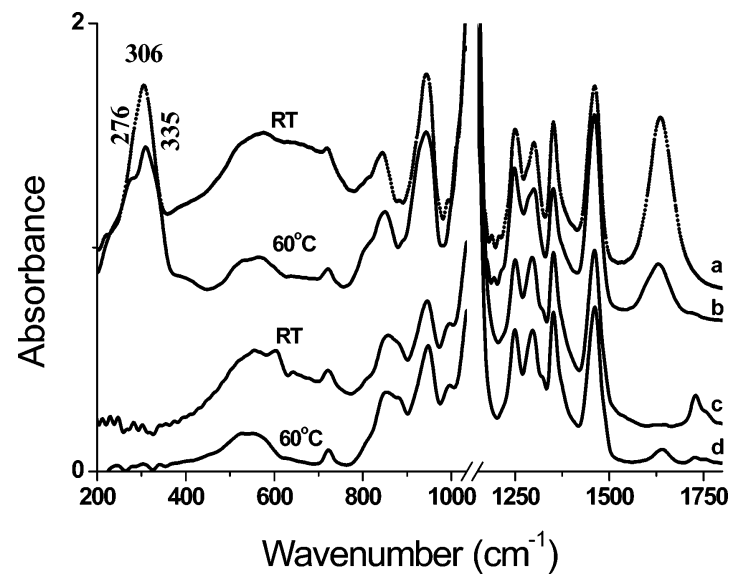

Figure 7. FTIR spectra of a $\left[\mathrm{Co}\left(\mathrm{H}_{2} \mathrm{O}\right)_{6}\right] \mathrm{Cl}_{2}: \mathrm{C}_{12} \mathrm{EO}_{10} \mathrm{LC}$ mesophase with a salt:surfactant mole ratio of 2.0 (a) at $30{ }^{\circ} \mathrm{C}$ and (b) at $60{ }^{\circ} \mathrm{C}$ and pure surfactant $\left(\mathrm{C}_{12} \mathrm{EO}_{10}\right)$ at (c) RT and (d) $60{ }^{\circ} \mathrm{C}$.

The $\left[\mathrm{Co}\left(\mathrm{H}_{2} \mathrm{O}\right)_{6}\right] \mathrm{Cl}_{2}: \mathrm{C}_{n} \mathrm{EO}_{m}$ samples were further investigated to elucidate the thermal properties. Heating the samples (both salt:surfactant, binary, and salt:water:surfactant, ternary, after complete evaporation of excess water) at approximately $60{ }^{\circ} \mathrm{C}$ disturbs the equilibrium conditions, changes the electronic absorption spectrum (not shown), and causes the samples to become isotropic in POM. However, the effects of heat are reversible; the spectrum and anisotropy could be recovered upon cooling and resting the samples at RT for 20-60 min. The heating/cooling cycle was repeated several times with all samples $\left[\mathrm{Co}\left(\mathrm{H}_{2} \mathrm{O}\right)_{6}\right] \mathrm{Cl}_{2}: \mathrm{C}_{n} \mathrm{EO}_{m}(n=12,16$, and $18 ; m=10$ and 20). Each time, the spectra and anisotropy were recovered. Also note that heating destroys the mesophase; as a result the diffraction line(s) disappear, but reappear upon cooling. It is clear from the trends from the evaporation process and thermal behaviors of the LC mesophase that coordinated water molecules (they can be removed by heating) are necessary for the organization of surfactant molecules into an LC mesophase.

FTIR spectroscopy has also been applied to identify the species during the above processes. The $v(\mathrm{CoCl})$ stretching mode of the $\left[\mathrm{CoCl}_{4}\right]^{2-}$ ion that is observed at $306 \mathrm{~cm}^{-1}$ splits into two new peaks at 276 and $335 \mathrm{~cm}^{-1}$ and a shoulder at around $230 \mathrm{~cm}^{-1}$ during the heating process. The surfactant signals at around $800-1000 \mathrm{~cm}^{-1}$ also respond to heating. Some of the surfactant $v(\mathrm{CO})$ stretching modes gain intensity, while some lose their intensities. The changes in the IR and UV-vis spectra collectively indicate metal-surfactant interactions upon the removal of coordinated water molecules. Unfortunately, Raman measurements could not be recorded for these samples due to the strong absorption and emission (the samples burn under a laser beam). Figure 7 also shows the same region of the pure $\mathrm{C}_{12} \mathrm{EO}_{10}$ at $\mathrm{RT}$ and $60{ }^{\circ} \mathrm{C}$ for comparison purposes. Note that there is no appreciable change in the spectra of pure surfactant by heating from RT to $60^{\circ} \mathrm{C}$. The spectral changes in the mid-IR (in the $v(\mathrm{CoCl})$ stretching regions and surfactant related peaks) and in the visible regions upon heating are evidence of the formation of a surfactant complex, $\left[\mathrm{Co}\left(\mathrm{C}_{n} \mathrm{EO}_{\mathrm{m}}\right)_{x^{-}}\right.$ $\mathrm{Cl}_{2}$ ]. However, this complex is not stable at RT and decays back to the equilibrium species upon readsorption of ambient water where the FTIR and visible absorption spectra of a sample that is heated and cooled are indistinguishable from that of the unheated samples.

Mixed-Salt Systems. To elucidate further the effects of counteranions on an LC mesophase, a series of $\left[\mathrm{Co}\left(\mathrm{H}_{2} \mathrm{O}\right)_{6}\right]-$ $\left.\left(\mathrm{NO}_{3}\right)_{2} /\left[\mathrm{Co}\left(\mathrm{H}_{2} \mathrm{O}\right)_{6}\right] \mathrm{Cl}_{2}: \mathrm{C}_{12} \mathrm{EO}_{10},\left[\mathrm{Cd}\left(\mathrm{H}_{2} \mathrm{O}\right)_{4}\right]\left(\mathrm{NO}_{3}\right)_{2} / \mathrm{Cd}\left(\mathrm{H}_{2} \mathrm{O}\right)_{4}\right]-$ $\left(\mathrm{ClO}_{4}\right)_{2}: \mathrm{C}_{12} \mathrm{EO}_{10}, \quad\left[\mathrm{Cd}\left(\mathrm{H}_{2} \mathrm{O}\right)_{4}\right]\left(\mathrm{NO}_{3}\right)_{2} /\left[\mathrm{Cd}\left(\mathrm{H}_{2} \mathrm{O}\right)_{4}\right] \mathrm{Cl}_{2}: \mathrm{C}_{12} \mathrm{EO}_{10}$, 
and $\left[\mathrm{Zn}\left(\mathrm{H}_{2} \mathrm{O}\right)_{6}\right]\left(\mathrm{NO}_{3}\right)_{2} /\left[\mathrm{Zn}\left(\mathrm{H}_{2} \mathrm{O}\right)_{6}\right]\left(\mathrm{ClO}_{4}\right)_{2}: \mathrm{C}_{12} \mathrm{EO}_{10}$ mesophases were prepared, and their equilibrium spectra were recorded. Note that the LC mesophases of $\left[\mathrm{Co}\left(\mathrm{H}_{2} \mathrm{O}\right)_{6}\right]\left(\mathrm{NO}_{3}\right)_{2}: \mathrm{C}_{12} \mathrm{EO}_{10}$ and [Co$\left.\left(\mathrm{H}_{2} \mathrm{O}\right)_{6}\right] \mathrm{Cl}_{2}: \mathrm{C}_{12} \mathrm{EO}_{10}$ are $2 \mathrm{D}$ hexagonal; however, the LC mesophases of $\left[\mathrm{Cd}\left(\mathrm{H}_{2} \mathrm{O}\right)_{4}\right]\left(\mathrm{NO}_{3}\right)_{2}: \mathrm{C}_{12} \mathrm{EO}_{10}$ and $\left[\mathrm{Cd}\left(\mathrm{H}_{2} \mathrm{O}\right)_{4}\right]\left(\mathrm{ClO}_{4}\right)_{2}$ : $\mathrm{C}_{12} \mathrm{EO}_{10}$ are $2 \mathrm{D}$ hexagonal and cubic, respectively.

In a $\left[\mathrm{Co}\left(\mathrm{H}_{2} \mathrm{O}\right)_{6}\right]\left(\mathrm{NO}_{3}\right)_{2} /\left[\mathrm{Co}\left(\mathrm{H}_{2} \mathrm{O}\right)_{6}\right] \mathrm{Cl}_{2}: \mathrm{C}_{12} \mathrm{EO}_{10}$ mixed-salt system, the intensity ratio of electronic absorption bands due to the $\left[\mathrm{CoCl}_{4}\right]^{2-}$ complex ion at $690 \mathrm{~nm}$ and $\left[\mathrm{Co}\left(\mathrm{H}_{2} \mathrm{O}\right)_{6}\right]^{2+}$ at $510 \mathrm{~nm}$ increases linearly with decreasing nitrate salt concentration (not shown). Also note that the visible absorption spectrum of the $\left[\mathrm{Co}\left(\mathrm{H}_{2} \mathrm{O}\right)_{6}\right]\left(\mathrm{NO}_{3}\right)_{2}: \mathrm{C}_{12} \mathrm{EO}_{10}$ system does not change with the coordination of the nitrate ion to the cobalt ion. Therefore, increasing the nitrate salt in the medium decreases the concentration of $\left[\mathrm{CoCl}_{4}\right]^{2-}$ and increases the concentration of the [Co$\left.\left(\mathrm{H}_{2} \mathrm{O}\right)_{6}\right]^{2+}$ or $\left[\mathrm{Co}\left(\mathrm{H}_{2} \mathrm{O}\right)_{4}\left(\mathrm{O}_{2} \mathrm{NO}\right)\right]^{+}$ion complex. The peaks due to the neutral complex $\left[\mathrm{Co}\left(\mathrm{H}_{2} \mathrm{O}\right)_{4} \mathrm{Cl}_{2}\right]$ at 454 and $530 \mathrm{~nm}$ disappear from the spectra of samples with a nitrate:chloride mole ratio of $\geq 0.8$. Most likely, unidentate and/or bidentate nitrate-coordinated species dominate over the neutral $\left[\mathrm{Co}\left(\mathrm{H}_{2} \mathrm{O}\right)_{4^{-}}\right.$ $\mathrm{Cl}_{2}$ ] complex. A similar trend is observed in the FTIR spectra of the above samples. By increasing nitrate salt in the medium, the nitrate signals gradually increase due to coordinated and free nitrate ions while the peak at around $306 \mathrm{~cm}^{-1}$ due to the $v(\mathrm{CoCl})$ stretching mode gradually decreases (not shown).

To expand the influence of ion density and/or ionic strength on a mesophase, a series of samples using both perchlorate and nitrate salts of the same metal that differ in the perchlorate: nitrate ratio have been prepared in $\mathrm{C}_{12} \mathrm{EO}_{10}$ with a metal-tosurfactant mole ratio of 2.0. Figure 8 shows the micro-Raman spectra of various zinc perchlorate/zinc nitrate and cadmium perchlorate/cadmium nitrate systems. The signals at around 935 $\mathrm{cm}^{-1}$ due to the perchlorate ion from both $\mathrm{Zn}$ (II) and $\mathrm{Cd}(\mathrm{II})$ salts are identical and do not change with the evaporation of excess water, Figure 8 . In the nitrate region of the spectra there are two peaks at 1030 and $1050 \mathrm{~cm}^{-1}$ due to the symmetric stretching mode of coordinated and free nitrate ions, respectively. In the case of the $\mathrm{Cd}(\mathrm{II})$ system, the intensity of the coordinated nitrate (at $1030 \mathrm{~cm}^{-1}$ ) is much higher compared to that of the free nitrate ion (at around $1050 \mathrm{~cm}^{-1}$ ), Figure 8B. Note that both nitrate and perchlorate ions are hydrotropic anions that make the surfactant molecules more hydrophilic. Also note that the nitrate ion coordinates to the metal ion, ${ }^{2}$ and the perchlorate ion remains free in the LC medium. Therefore, the ion density or ionic strength increases with increasing perchlorate salt concentration in the perchlorate/nitrate mixed-salt: surfactant systems that favor the equilibrium reaction (eq 1) (between the free and coordinated nitrate ion) to shift to the right, favoring the nitrate-coordinated metal ion species, Figure $8 \mathrm{~B}$.

The perchlorate/nitrate systems were further investigated using both POM and XRD techniques. The POM images of the samples of low perchlorate:nitrate ratios show anisotropy, but the image closely resembles that of a $3 \mathrm{D}$ hexagonal mesophase, Figure 1B. However, the mesophase changes from a 3D hexagonal to a $2 \mathrm{D}$ hexagonal mesophase in a few days (i.e., the POM image changes to a focal conic fan texture; note also that the 2D and 3D hexagonal mesophases of nitrate salts are stable for years). A similar behavior was observed in the pure nitrate systems, in the presence of excess water (ternary system), during the water evaporation process. First an anisotropy appears with a texture very similar to that shown in Figure $1 \mathrm{~B}$ and then eventually ends with the image in Figure 1A with further evaporation. Figure 9 shows the XRD patterns of

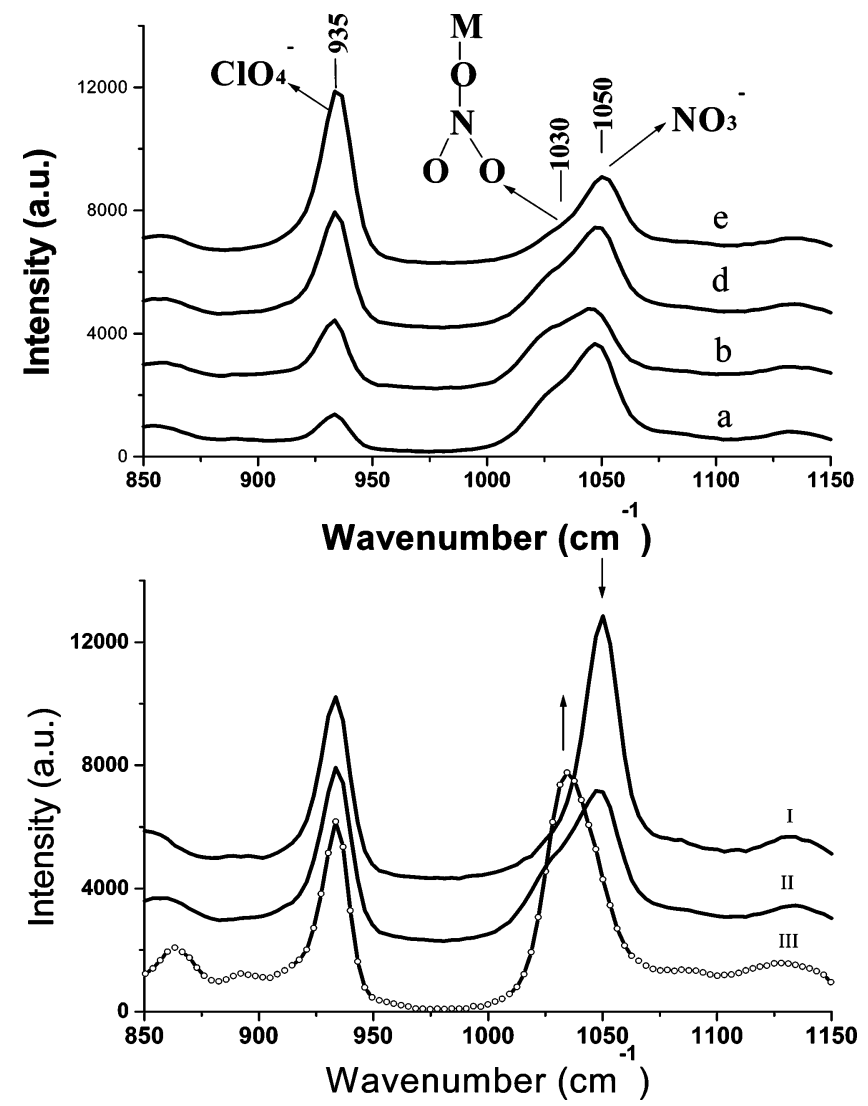

Figure 8. (A, top) Micro-Raman spectra of $\left[\mathrm{Zn}\left(\mathrm{H}_{2} \mathrm{O}\right)_{6}\right]\left(\mathrm{ClO}_{4}\right)_{2} /[\mathrm{Zn}$ $\left.\left(\mathrm{H}_{2} \mathrm{O}\right)_{6}\right]\left(\mathrm{NO}_{3}\right)_{2}: \mathrm{C}_{12} \mathrm{EO}_{10}$ with perchlorate:nitrate mole ratios of (a) 1.0: 1.0, (b) $1.2: 0.8$, (c) 1.4:0.6, (d) 1.6:0.4, and (e) 1.8:0.2. (B, bottom) Micro-Raman spectral changes around the nitrate symmetric stretching and perchlorate stretching regions with the evaporation of water: (I) water-rich sample, (II) sample with an intermediate concentration of water, and (III) sample after complete water evaporation.

mixtures of 0.0:2.0 (cubic), 1.5:0.5 (3D hexagonal) and 1.8:0.2 (2D hexagonal) mole ratios of $\left[\mathrm{Cd}\left(\mathrm{H}_{2} \mathrm{O}\right)_{4}\right]\left(\mathrm{NO}_{3}\right)_{2} /\left[\mathrm{Cd}\left(\mathrm{H}_{2} \mathrm{O}\right)_{4}\right]-$ $\left(\mathrm{ClO}_{4}\right)_{2}$ with $1 \mathrm{~mol}$ of $\mathrm{C}_{12} \mathrm{EO}_{10}$ for comparison purposes. In the cubic $\left[\mathrm{M}\left(\mathrm{H}_{2} \mathrm{O}\right)_{n}\right]\left(\mathrm{ClO}_{4}\right)_{2}: \mathrm{C}_{n} \mathrm{EO}_{\mathrm{m}}$ systems, we observed that the diffraction pattern is very dynamic in that every simultaneous measurement gives a different set of diffraction lines of the $P n 3 m$ cubic mesophase. ${ }^{3}$ The XRD pattern of the 1.5:0.5 sample consists of seven diffraction lines at $2 \theta=1.74^{\circ}, 1.85^{\circ}, 1.98^{\circ}$, $2.58^{\circ}, 2.78^{\circ}, 3.70^{\circ}$, and $4.36^{\circ}$, corresponding to the (100), (002), (101), (102), (201), (004), and (203) lines of a 3D hexagonal phase, Figure 9B. The unit cell parameters $a=58.3 \AA$ and $c=$ $95.4 \AA$ with $c / a=1.636$ are consistent with the $P 6_{3} \mathrm{~mm}$ space group of a 3D hexagonal mesophase. The XRD pattern also changes in time (several days), correlating the changes observed under POM. The pattern displays two lines due to the (100) and (200) planes of a 2D hexagonal phase. The POM image and XRD pattern are identical to those of pure nitrate binary systems. Most likely the perchlorate salts crystallize out of the mesophase in time, leaving a nitrate-rich mesophase.

Since nitrate and chloride ions coordinate to a metal ion and decrease the ionic strength or the ion density of the medium, the ternary systems have a higher ionic strength or ion density compared to those of evaporated samples (binaries). The surfactant molecules in the system sense the ion density and/or ionic strength of the medium such that they organize themselves to maximize the hydrophilic surface for the accommodation of these ions. Therefore, the ionic strength of the mixtures is an important parameter for the stability and also a determining 

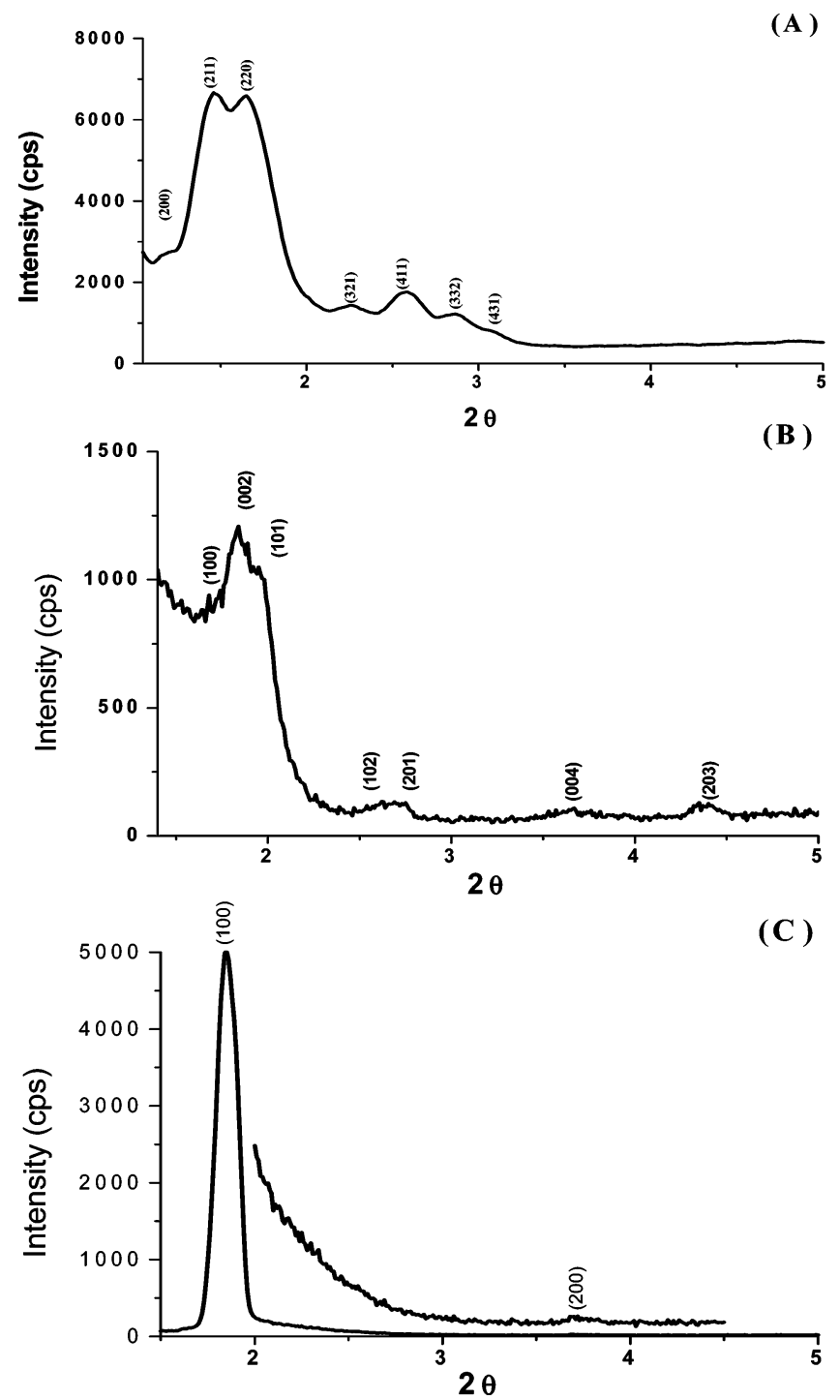

Figure 9. XRD pattern of $\left[\mathrm{Cd}\left(\mathrm{H}_{2} \mathrm{O}\right)_{4}\right]\left(\mathrm{NO}_{3}\right)_{2} /\left[\mathrm{Cd}\left(\mathrm{H}_{2} \mathrm{O}\right)_{4}\right]\left(\mathrm{ClO}_{4}\right)_{2}: \mathrm{C}_{12^{-}}$ $\mathrm{EO}_{10}$ mixed-salt systems. The nitrate-to-perchlorate mole ratios are (A) 0.0:2.0, (B) 1.5:0.5, and (C) 1.8:0.2 (the metal ion-to-surfactant mole ratio is 2.0 in all samples).

factor for the structure of an LC mesophase. It is also important to note that the solubility of the salt is another determining factor in the formation of an LC mesophase in a salt:surfactant system. For example, the chloride salts are almost insoluble (except cobalt chloride) in nonionic surfactants; however, the perchlorate salts are soluble even though these two salt systems may have similar ionic strengths in the LC medium. Furthermore, the ionic strength in a perchlorate system is much higher compared to that in nitrate systems, but the $\mathrm{LC}$ phase of a $\left[\mathrm{Cr}\left(\mathrm{H}_{2} \mathrm{O}\right)_{6}\right]\left(\mathrm{ClO}_{4}\right)_{3}$ : $\mathrm{C}_{12} \mathrm{EO}_{10}$ binary system, which contains $\left[\mathrm{Cr}\left(\mathrm{H}_{2} \mathrm{O}\right)_{6}\right]^{3+}$ and three $\mathrm{ClO}_{4}{ }^{-}$ions with a relatively large ionic strength, exists and is stable for a few days.

Our findings also corroborate the recent calculations by Sachs and Woolf ${ }^{35}$ through molecular dynamic simulation of hydrotropic anions in lipid bilayers toward understanding the Hofmeister effects. The authors demonstrated that the large hydrotropic anions are more hydrophobic and penetrate more into interfacial regions of the lipid bilayers, causing conformational changes in the lipid molecules. ${ }^{35}$ Similarly, the more hydrophobic perchlorate ion prefers the alkyl tail/ethoxy headgroup interface region as compared to the nitrate ion. There must be an equilibrium between the perchlorate ions in the alkyl tail/ethoxy headgroup interface and in the polar ethoxy regions of the mesophase. Further studies are required to understand the conformational changes happening in various salt system which will further enhance our molecular understanding of the Hofmeister series in the salt:surfactant LC systems.

\section{Conclusion}

In summary, the transition-metal salts with $\mathrm{C}_{n} \mathrm{EO}_{m}$ nonionic surfactants form LC mesophases that are sensitive to the anion type of the salts and the ion density (or ionic strength) of the LC medium. The trend in the Hofmeister series is effective in the solubility of transition-metal salts; however, the coordination of the counteranion to the metal ion plays a very important role in the solubility and in the formation of the LC mesophase. There are two factors which affect the stability and the structure type of salt:surfactant systems. (1) The hydrophilicity of the $\mathrm{C}_{n} \mathrm{EO}_{m}$ nonionic surfactant, which is influenced by the anions in the direction of the Hofmeister series. The lyotropic anions, such as chloride and sulfate make the surfactant molecules hydrophobic; on the other hand, the hydrotropic anions, such as nitrate and perchlorate ions, make them more hydrophilic. This enhances the solubility of the hydrotropic salts in $\mathrm{C}_{n} \mathrm{EO}_{m}$ surfactants. (2) The coordination of anions to metal ions, which reduces the ionic strength of the medium, such that it prevents the crystallization of the salt in the LC medium. By controlling the ion density or the ionic strength of the mesophase, one can control the structure of the LC mesophase.

The salt: $\mathrm{C}_{n} \mathrm{EO}_{m} \mathrm{LC}$ systems are also sensitive to temperature, such that at a high temperature, due to loss of coordinated water molecules, a disordered phase appears; however, upon cooling and readsorption of ambient water, the LC mesophase re-forms. Therefore, the type and concentration of ions and the temperature of the medium are important in the formation, structure, and stability of the LC salt:surfactant mesophase.

Acknowledgment. For financial support, Ö.D. gratefully acknowledges the Scientific and Technical Research Council of Turkey (TÜBITAK) in the framework of Project TBAG2263 (102T188), the Turkish Academy of Science in the framework of a Young Scientist Award (ÖD/TÜBA-GEBIP/ 2002-1-6), and Bilkent University in the framework of a faculty development grant.

\section{References and Notes}

(1) Çelik, Ö.; Dag, Ö. Angew. Chem., Int. Ed. 2001, 40, 3800.

(2) Dag, Ö. Samarskaya, O.; Tura, C.; Günay, A.; Çelik, Ö. Langmuir 2003, 19, 3671 2711 .

(3) Dag, Ö.; Alayoğlu, S.; Tura, C.; Çelik, Ö. Chem. Mater. 2003, 15,

(4) Schott, H. J. Colloid Interface Sci. 1997, 192, 458.

(5) Iwanaga, T.; Suzuki, M.; Kunieda, H. Langmuir 1998, 14, 5775.

(6) Rodriguez, C.; Kunieda, H. Langmuir 2000, 16, 8263.

(7) Atard, G. S.; Bartlett, P. N.; Coleman, N. R. B.; Elliott, J. M.; Owen Langmuir 1998, 14, 7340.

(8) Yu, C.; Tian, B.; Fan, J.; Stucky, G. D.; Zhao, D. J. Am. Chem. Soc. 2002, 124, 4556

(9) Leontidis, E. Curr. Opin. Colloid Interface Sci. 2002, 7, 81.

(10) Che, S.; Lim, S.; Kaneda, M.; Yoshitake, H.; Terasaki, O.; Tatsumi, T. J. Am. Chem. Soc. 2002, 124, 13692.

(11) Hofmeister, F. Arch. Exp. Pathol. Pharmakol. 1888, 24, 247.

(12) Iwanaga, T.; Suzuki, M.; Kunieda, H. Langmuir 1998, 14, 5775.

(13) Attard, G. S.; Göltner, C. G.; Corker, J. M.; Henke, S.; Templer, R. H. Angew. Chem., Int. Ed. Engl. 1997, 36, 1315.

(14) Attard, G. S.; Bartlett, P. N.; Coleman, N. R. B.; Elliott, J. M.; Owen, J. R.; Wang, J. H. Science 1997, 278, 838.

(15) Braun, P. V.; Osenar, P.; Stupp, S. I. Nature 1996, 380, 325

(16) Osenar, P.; Braun, P. V.; Stupp, S. I. Adv. Mater. 1996, 8, 1022.

(17) Braun, P. V.; Osenar, P.; Tohver, V.; Kennedy, S. B.; Stupp, S. I. J. Am. Chem. Soc. 1999, 121, 7302. 
(18) Jiang, X.; Xie, Y.; Lu, J.; Zhu, L.; He, W.; Qian, Y. Chem. Mater. 2001, 13, 1213.

(19) Bagshaw, S. A.; Prouzet, E.; Pinnavaia, T. J. Science 1995, 269, 1242.

(20) Miyata, H.; Itoh, M.; Watanabe, M.; Noma, T. Chem. Mater. 2003 , $15,1334$.

(21) Dag, Ö.; Verma, A.; Ozin, G. A.; Kresge, C. T. J. Mater. Chem. 1999, 9,1475

(22) Samarskaya, O.; Dag, Ö. J. Colloid Interface Sci. 2001, 238, 203.

(23) Dag, Ö.; Samarskaya, O.; Coombs,N.; Ozin, G. A. J. Mater. Chem. 2003, 13, 328

(24) Dag, Ö.; Soten, I.; Celik, O.; Polarz, S.; Coombs, N.; Ozin, G. A. Adv. Funct. Mater. 2003, 13, 30 .

(25) Halla, J. D.; Mamak, M.; Williams, D. E.; Ozin, G. A. Adv. Funct. Mater. 2003, 13, 133.

(26) Reppy, M. A.; Gray, D. H.; Pindzola, B. A.; Smithers, J. L.; Gin, D. L. J. Am. Chem. Soc. 2001, 123, 363.
(27) Zhao, D. Y.; Huo, Q. S.; Feng, J. L.; Chmelka, B. F.; Stucky, G. D. J. Am. Chem. Soc. 1998, 120, 6024.

(28) Yang, H.; Shi, Q.; Tian, B.; Xie, S.; Zhang, F.; Yan, Y.; Tu, B.; Zhao, D. Chem. Mater. 2003, 15, 536.

(29) Blin, J. L.; Leonard, A.; Su, B. L. J. Phys. Chem. B 2001, 105, 6070 .

(30) Dag, Ö.; Yoshina-Iskii, C.; Asefa, T.; MacLachlan, M. J.; Grondey, H.; Coombs, N.; Ozin, G. A. Adv. Funct. Mater. 2001, 11, 213-217.

(31) Attard, G. S.; Glyde, J. C.; Göltner, C. G. Nature 1995, 378, 366. (32) Evans, J.; Zaki, A. B.; El-Sheikh, M. Y.; El-Safty, S. A. J. Phys. Chem. B 2000, 104, 10271.

(33) Cotton, A. F.; Wilkinson, G. Advanced Inorganic Chemistry, 5th ed.; Wiley: New York, 1988; p 727.

(34) Lever, A. B. P. Inorganic Electronic Spectroscopy, 2nd ed.; Elsevier: New York, 1984; pp 479-490.

(35) Sachs, J. N.; Woolf, T. B. J. Am. Chem. Soc. 2003, 125, 8742. 